\title{
Erratum: Critics pan timid European response to TeGenero disaster
}

Peter Mitchell

Nature Biotechnology 25, 485-486 (2007); published online 6 April 2007

In the version of this article originally published, the performance of the UK Medical and Healthcare Products Regulatory Agency (MHRA) is described in the sentence of the penultimate paragraph in the $2^{\text {nd }}$ column on p. 486 as follows: "As the BIA points out, that would make the entire CTA process take an absolute minimum of 11 weeks." According to MHRA, however, this is wholly incorrect and completely exaggerates the time taken. Full assessments of time-based performance of MHRA can be found at: http://www.mhra.gov.uk/home/idcplg?IdcService=SS_GET_

\section{Erratum: Tech transfer fails to translate into startups}

Stacy Lawrence

Nature Biotechnology 25, 616 (2007); published online 30 April 2007

In the version of this article originally published, the second sentence incorrectly stated "In its annual survey, the Association of University Technology Managers (AUTM) estimates tech transfer resulted in 527 new products and 628 new firms in 2005, about one-sixth of which were life-science based." The sentence should have read: "In its annual survey, the Association of University Technology Managers (AUTM) estimates tech transfer resulted in 527 new products and 628 new firms in 2005. Life sciences-oriented hospitals and research institutes are thought to account for roughly one-sixth of licenses. In addition, in the pie charts appearing at the bottom right, the AUTM figures shown are for all small companies, not specifically for biotech firms. At the top right, the US National Institutes of Health (NIH) tech transfer activities identified on the chart are only those from the intramural research programs of both NIH and the US Food and Drug Administration; they do not reflect the tech transfer activities of NIH extramural grantees, who represent $83 \%$ of the total NIH funding." 